\title{
Sobre la construcción y restauración de la iglesia sevillana de San Bartolomé y su torre
}

\author{
José Manuel Higuera Meléndez \\ Doctor Arquitecto
}

\begin{abstract}
Resumen: El objetivo del presente trabajo es aportar una nueva lectura y la puesta al día del proceso edificatorio del templo hispalense de San Bartolomé y su torre, actualmente en restauración, recorriendo su historia constructiva, parcialmente recogida en las fuentes documentales originales, tanto en el expediente diocesano de la obra de nueva planta, como en los posteriores de reparaciones y reformas. El detonante de la investigación ha sido la propuesta de reconstruir el perdido remate de la torre, que el proyecto de restauración considera parte del diseño original de la misma. Sin embargo, el análisis de la documentación existente y el bagaje de conocimientos ya adquirido, demuestran sin duda su adscripción a un momento artístico muy posterior. Al respecto, se ofrece por último una reflexión personal sobre la intervención en arquitecturas de épocas pretéritas.
\end{abstract}

\begin{abstract}
The target of the present drafting is to provide a new concept as well as updating the building process in the San Bartolome temple by Seville and its tower, currently under restoration, throughout its constructive history, partially gathered by original documentary sources, both -conception and updatingtaken from the new plant works trusted in the diocesan records and in the subsequent repairing jobs and modifications. The trigger of the investigation is the proposal of remaking the believed original design of the long-lost crowning of the tower in this new rebuilding project. However, the analysis of the available information as well as the stock of knowledge already stored claim without a doubt its belonging to a much later artistic moment. In this matter, we finally give a personal view on the building-intervention policy in former architectural styles.
\end{abstract}




\section{INTRODUCCIÓN}

La limpia y renovada apariencia interior de la iglesia hispalense de San Bartolomé, cuyas naves, capillas y dependencias fueron restauradas a finales del siglo pasado, contrasta notablemente con la imagen externa de abandono del templo, significativa muestra del tardobarroco sevillano, que goza desde 1997 de la declaración como Bien de Interés Cultural. Construido entre 1779 y $1800^{1}$, muchos años de descuido en el mantenimiento y conservación de sus elementos exteriores, han ido ocasionado un progresivo y más que evidente deterioro en la piel esgrafiada del monumental inmueble, cuyas fachadas, portadas y torre presentan hoy día la pérdida de buena parte de sus revestimientos, remates, azulejería y cerrajería, así como la existencia de grietas y roturas en cornisas, balcones y detalles decorativos. De entre los reseñados, es sin duda la esbelta y esquinera torre, el elemento arquitectónico que más concita la atención, concentrándose también en ella profusos y notables daños, provocados fundamentalmente por la ausencia de remate desde los pasados años cincuenta, cuando se produjo la caída del cupulín de planta octogonal y apuntado perfil que la coronaba. Dicho remate protegía el óculo de comunicación vertical abierto sobre el cuerpo de campanas, que ha permanecido desde entonces a merced de las lluvias.

Felizmente, tras haberse acometido unas obras de urgencia en 2015, dirigidas a consolidar las fachadas para detener su deterioro y salvaguardar los elementos susceptibles de caer a la vía pública, en noviembre de 2016 fue aprobado por la Comisión Provincial de Patrimonio el"Proyecto de restauración de la torre campanario de la iglesia de San Bartolomé de Sevilla", redactado por la doctor arquitecto María Dolores Robador González, reconocida profesional especializada en la restauración monumental. Encargado por la archidiócesis, el proyecto incluye una reseña histórica y constructiva del edificio ${ }^{2}$, contemplando una serie de intervenciones divididas en fases, la primera de las cuales se refiere, por evidentes motivos de urgencia, a detener la ruina de la torre, consolidar el campanario, proteger sus fábricas y recuperar sus revestimientos. En esta etapa, como solución para evitar la entrada en la torre del agua llovediza, se propone la realización de una cubierta a cuatro aguas sobre estructura metálica, no visible desde la vía pública. Al mismo tiempo se repararán las fisuras y se reforzarán estructuralmente las zancas y los muros de la torre, consolidándose pretiles y balcones. Finalmente, se restaurarán los revestimientos de muros y los pavimentos, así como los elementos de cerrajería y las campanas. El proyecto prevé en posteriores fases una serie de actuaciones futuras, entre las que destaca la"re-instauración de la cúpula (de remate de la torre) recuperando

\footnotetext{
Según la bibliografía más acreditada, el templo se inauguró oficialmente en ese año.

2 Basada principalmente en el detallado artículo deVILELA GALLEGO, Pilar:“San Bartolomé de Sevilla", Archivo Hispalense, n 222, Sevilla, 1990.
} 
la original". Al respecto, en el documento se adjuntan algunas fotografías de la primera mitad del siglo pasado con la desaparecida pieza esquifada, que el proyecto identifica como el remate original, mediante cuya reposición se propone recuperar el estado prístino de la torre.

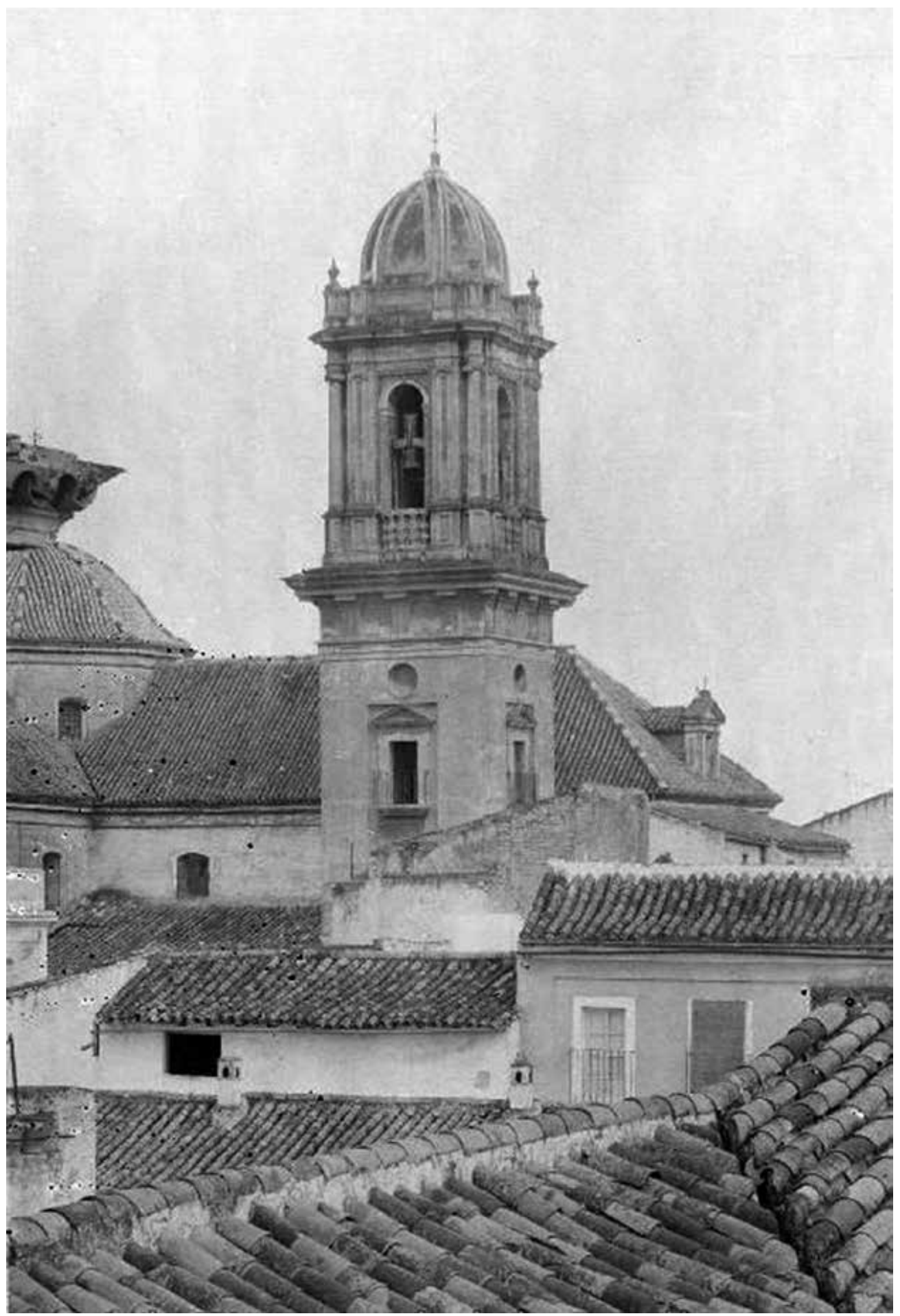

La torre de San Bartolomé a principios del pasado siglo. Se aprecia el remate de planta octogonal y lados desiguales que la coronó hasta mediados de la centuria y que ahora se pretende recuperar. También es visible el tejado a un agua que cubría el lado del evangelio, posteriormente transformado en cubierta plana. Copyright Universidad de Sevilla 
Sin embargo, a la vista de los citados testimonios gráficos, diríase que dicho remate no guarda relación estilística, formal ni conceptual con la arquitectura del templo, ya que esta coronación en forma de cupulín de apuntada sección vertical resulta completamente inusual y alejada de los habituales modelos diocesanos de la época, en los que predomina el tradicional chapitel piramidal sobre rebanco de planta ochavada regular, en ocasiones sustituido por remates más elaborados de mixtilíneos perfiles y elementos yuxtapuestos. Lo cual hace generar cierta cautela al respecto de que la re-instauración prevista en el proyecto vaya a devolver su primitiva apariencia al campanario de San Bartolomé. Parecía, pues, ser éste un momento idóneo para repasar y, en su caso, poner al día el proceso edificatorio del templo, recorriendo su historia constructiva mediante la consulta y análisis de fuentes documentales originales, como el expediente diocesano de la obra ${ }^{3}$. Ligados a la realización del nuevo templo de San Bartolomé aparecen reputados personajes de la sevillana esfera arquitectónica de la época, cada uno de los cuales intervino con distinto grado de protagonismo, desde los maestros proyectistas hasta los directores de obra, pasando por quienes la ejecutaron materialmente. E incluso por un maestro constructor designado por la diócesis que, debido a presiones de la fábrica parroquial, se vio obligado a renunciar.

Con frecuencia, la obra de un artista, en nuestro caso de un arquitecto o maestro mayor, es reconocible frente a la de sus colegas coetáneos merced a la existencia de estilemas o tics característicos que constituyen una impronta personal. De igual manera, la afortunada realización de ciertos edificios que se convierten en hitos de su labor profesional, otorga al arquitecto la posibilidad de reiterar o reinterpretar en posteriores ocasiones el modelo original. Pues bien, en San Bartolomé se verifican ambas circunstancias, de modo que a pesar del dilatado período de ejecución del templo y de los diferentes maestros que participaron en su construcción, es posible atribuir a cada uno de ellos, con un elevado grado de certeza, los jalones fundamentales de su azarosa historia constructiva, incluida la torre. Además, al finalizar el expediente de la obra en 1796, fecha en la que no estaba construido aún el cuerpo de campanas, ha sido necesario ampliar el estudio documental hasta bien entrada la siguiente centuria. Como se verá, la presente investigación demuestra que lo que se conseguiría con la reconstrucción del remate perdido sería, en realidad, recuperar un elemento diseñado y ejecutado en la segunda mitad del siglo XIX.

De acuerdo con el discurso del expediente diocesano, el relato del proceso constructivo del templo se ha dividido aquí en cuatro capítulos ordenados cronológicamente. Un quinto apartado, finalizado ya el expediente de las obras, presenta hipótesis y conclusiones propias, basadas en el conocimiento de la

3 Archivo General del Arzobispado de Sevilla, AGAS, Fondo Arzobispal, Sec. III, sign. 11473. 
arquitectura diocesana del dieciocho ${ }^{4}$, que hacen hincapié en la formalización prevista por su último proyectista para la inacabada torre y en la confirmación de la filiación tardo-ochocentista del remate desaparecido a mediados del siglo pasado. De esta manera, resulta inevitable abordar igualmente la cuestión de cómo acometer una intervención en arquitecturas de épocas pasadas, aplicada al caso concreto de la torre de San Bartolomé.

\section{LA IGLESIA PREEXISTENTE (1778-1780)}

11 de agosto de 1778: El procurador de fábricas del arzobispado, en nombre de la fábrica de la iglesia parroquial de San Bartolomé, solicita la visita del maestro mayor de albañilería del arzobispado junto con el de carpintería, a fin de reconocer las obras que necesita la vetusta iglesia parroquial ${ }^{5}$. Este mismo día firma su informe Francisco delValle, maestro mayor carpintero.

22 de agosto de 1778: Tras girar visita a la iglesia, Pedro de Silva presenta informe en el que destaca el mal estado de los tejados de sus tres naves y del resto de dependencias, los cuales habrá que rehabilitar, así como la pérdida de verticalidad de las paredes que gravitan sobre las dos líneas de arcos sobre columnas y pilares (6 columnas y 4 pilares) que separan la nave central de las laterales. Silva propone derribar ambas líneas de carga, dando las prescripciones para su reconstrucción y advirtiendo custodiar con gran cuidado las columnas de piedra para reponerlas en su sitio, "porque de la Piedra que son oy no la hay en parte alguna". El maestro propone reconstruir las naves con la orden jónica, cuyos elementos (zócalos, basas, capiteles, arquitrabes,...) prevé ejecutar con piedra de Estepa o de Gerena. El informe de Silva prescribe también ciertas labores en la pared y dos testeros de la sala sobre la sacristía, reparación de la azotea del campanario y castillete de la escalera, ascendiendo el presupuesto a 42.500 reales de vellón ${ }^{6}$.

29 de mayo de 1779: El procurador del Deán y Cabildo catedralicio, no conforme con este parecer, solicita la visita del maestro mayor Antonio de Figueroa

4 Conocimiento continuadamente adquirido a raíz de acometer mi tesis doctoral: “La iglesia de San Pedro Apóstol de Peñaflor (Sevilla). Paisaje, arquitectura y construcción en el contexto clasicista de finales del siglo XVIII", leída en la Universidad de Sevilla el 20 de enero de 2016 con la calificación de sobresaliente" cum laude".

5 Siguiendo el procedimiento establecido, el procurador mayor de fábricas transmitía el requerimiento de obras realizado por la fábrica parroquial al provisor arzobispal, quien ordenaba finalmente la visita de reconocimiento del maestro mayor de albañilería, de carpintería o de ambos. En el caso de San Bartolomé, como se puede observar, esta operación fue realizada en tiempo récord. En ese momento, la diócesis disponía de tres maestros mayores de albañilería nombrados oficialmente, que eran, por orden jerárquico, Pedro de Silva, Antonio de Figueroa y Vicente de San Martín. A San Bartolomé será enviado en primer lugar Pedro de Silva.

6 El viejo templo de San Bartolomé ocupaba desde finales del siglo XIV una antigua sinagoga. Presentaba la misma orientación que el actual y planta de tres naves con columnas y pilares, disponiendo de capillas adosadas y espadaña ubicada sobre el muro del cabecero. 
para que declare tanto si las obras prescritas por Silva son de urgente necesidad, como si deben ejecutarse con arreglo a sus condiciones ${ }^{7}$. La visita de Figueroa es autorizada por el provisor arzobispal.

19 de mayo de 1779: Habiendo reconocido el templo, Antonio de Figueroa presenta informe ratificando la necesidad de las obras, aunque no comparte que se repongan las columnas existentes, "porque las dichas son de una Piedra tosca y de ningun lucimiento". Pareciéndole más conveniente reducir de seis a cuatro los arcos intercolumnios (de 6 varas de luz), con tres pilares por línea (de 4 pies de frente y 3 de grueso) y medias muestras en los extremos, faltándoles sólo una vara para la proporción dupla. De esta manera también se favorecería la idea presentada por Silva de elevar la armadura de la nave mayor ${ }^{8}$.

1 de junio de 1779: El provisor otorga licencia para que se ejecuten las obras con arreglo al parecer de Antonio de Figueroa'.

19 de agosto de 1779: El procurador del Deán y Cabildo solicita que, puesto que ya se encuentra destechada la iglesia y derribados sus arcos, pase Figueroa a visitarla.

26 de agosto de 1779: Antonio de Figueroa presenta informe del nuevo reconocimiento, en el que expone la necesidad de derribar también, debido a su mala calidad, las gualderas, el testero y el cabecero de la iglesia, lo que podría conllevar asimismo la reconstrucción de las capillas y dependencias anexas al templo ${ }^{10}$. Sin embargo, Figueroa aclara que no acometerá el proyecto en tanto no se le autorice, a él o a otro maestro mayor, a formar plano, valoración y condiciones de las nuevas obras.

7 Los“Sres. Deán y Cabildo de la Santa Iglesia Patriarcal de Sevilla”, como administradores únicos y perpetuos de las rentas decimales de ella y su arzobispado, es decir, de los diezmos eclesiásticos, se mostraban reticentes ante grandes dispendios de caudales, por lo que solían solicitar el parecer de otro maestro mayor que confirmase o descartase la opinión del primero. La discrepancia en sus dictámenes, por lo que significaban de desautorización de un colega, cuando no de su sustitución por el discrepante al frente de las obras requeridas, generó no pocos rencores y desencuentros entre los maestros mayores.

8 Por tanto, mientras Pedro de Silva, más conservador en su propuesta inicial, formula rehabilitar la iglesia mediante la reposición de los soportes originales (columnas) y una barroquización tectónica de la nave central, Antonio de Figueroa ya plantea establecer en San Bartolomé el modelo barroco diocesano de templo de tres naves, levantando dos líneas de carga completamente nuevas, con arquerías sustentadas por los característicos pilares de planta cuadrangular y ajustadas en sus proporciones y elementos definitorios a los órdenes clasicos. Justamente un mes atrás había sido enviado Figueroa a Peñaflor a ratificar o no el parecer de Pedro de Silva respecto de la intervención a llevar a cabo en la vetusta iglesia de la villa.Y al igual que en San Bartolomé, mientras Silva propuso su reparación y una pequeña ampliación, Antonio de Figueroa justificó la conveniencia de su derribo para construir un nuevo templo más funcional y capaz, propuesta que fue la finalmente aprobada por el Cabildo.

9 A pesar de que el proyecto de Antonio de Figueroa conllevaba un dispendio mayor que el de Silva, también aquí el Cabildo valoró positivamente las razonadas explicaciones justificativas y la lógica convincente del discurso del maestro. De esta manera, los derribos prescritos en su parecer por Figueroa comenzaron a ejecutarse de inmediato.

10 Por tanto, queda claro que la idea de Figueroa tras su segundo reconocimiento era demoler por completo el edificio existente y construir un nuevo templo desde cimientos. 
19 de octubre de 1779: Paralelamente a los trámites oficiales, se había presentado ante la Diputación de Negocios del Deán y Cabildo catedralicio un proyecto de reconstrucción que aprovechaba parte de los muros antiguos de la iglesia, acompañando pliego de condiciones y planos de planta y alzados. Dicho proyecto fue supervisado por el maestro mayor del Cabildo, José Álvarez, quien lo aprobó y valoró en un mínimo de 400.000 reales, emitiendo su informe en este día ${ }^{11}$.

4 de diciembre de 1779: El provisor arzobispal otorga licencia para ejecutar los derribos expuestos por Figueroa y para que se haga el plano de la nueva iglesia.

7 de enero de 1780: Antonio de Figueroa es notificado de la autorización.

10 de enero de 1780: Informe de Antonio de Figueroa, en el que presenta el plano y las condiciones para las obras de reedificación de la iglesia de San Bartolomé, "diziendo ser lo mas sucinto y de menos costo que se puede executar en la dicha Yglesia y sin faltar a la desencia del buen Artte y Distribucion de sus Naves, Capillas y demas servidumbres, particularmente de las que siempre ha carecido".

Figueroa prescribe mantener algunos muros del viejo templo, "por Razon de sus muchos gruezos", concibiendo una iglesia de tres naves separadas por pilares, con crucero y cabecero, ubicándose a los pies el coro y sobre éste la tribuna para el órgano. También proyecta capilla bautismal, cuarto de colecturía, cuarto taller y el de la caja de escalera. La estructura de soporte de los tejados será de madera, de cerchas en la nave central y de colgadizo en las laterales, cubiertas interiormente con bóveda de cañón con lunetos y arcos fajones de madera enlistonada ("por escusar de maior gravedad y empujo") y con bóvedas por arista de tabique sencillo, respectivamente. También serán de cañón de lunetos de tabique sencillo las bóvedas de los brazos del crucero, en tanto que la de la tribuna del órgano será terciada con lunetos y de tabique doble. En el centro del crucero se formará el cuerpo de luces, que será ochavado exteriormente, quedando adornado por la parte interior con arquitrabe, friso, cornisa y banquillo y media naranja de rosca de ladrillo sin tambor ni ventanas. El orden interior será el dórico, "advirtiendo que el dicho Alquitrave y frizo no se ha de mover mas que es en las Pilastras y demas resaltos en donde Corresponde, y por sima de los dichos Arcos no Correrá mas que la Orla, con su mensola en la Clave y un motilo que ate el resalto hasta la Corona de la dicha Cornisa". Se dejará una ventana sobre cada uno de los cuatro arcos intercolumnios (dos por línea) y otra en el brazo del crucero del lado de la epístola, así como claraboyas a los pies de la iglesia, en tribuna y coro y en la capilla bautismal. Sobre los tejados, una buharda a cada costado de la armadura de la nave mayor, y otras

11 El profesor Sancho Corbacho afirma que dicho proyecto era obra de José Echamorro, aunque en el documento original, reproducido en el apéndice documental, no se cita al autor del mismo. 
más pequeñas en cada colgadizo del crucero y dos en cada uno de las naves menores. El presbiterio estará elevado tres gradas y dos el coro, que serán realizadas con piedra encarnada de Morón. Figueroa propone construir un cañón subterráneo en la nave central, y ejecutar la cubierta del pórtico del lado del evangelio con bóveda vaída tabicada, armadura en tosco y tejado de canal y redoblón a lomo cerrado, comprometiéndose a presentar "a su tiempo" las alturas de los elementos con el correspondiente alzado. El maestro valora las obras, incluida la reparación de la sacristía, en 263.538 reales de vellón, a los que hay que añadir la reparación de las capillas de Patronato, nuevos almacén y sala de cabildo para la Hermandad Sacramental, reedificación de las capillas de S. Francisco de Sena, de la Natividad de Nuestra Señora y de S. Jerónimo, que ascienden a 29.296 reales, pudiendo incluirse la reedificación de la capilla de Sta. Catalina y la ejecución del pórtico de entrada del lado de la epístola en el presupuesto principal $^{12}$.

\section{PRIMERA FASE DE LAS OBRAS DE LA NUEVA IGLESIA (1780-1782)}

24 de mayo de 1780: José Echamorro, maestro nombrado por el Deán y Cabildo para la ejecución de la nueva iglesia, arrienda una casa en la calle Escuderos (actual Garci-Pérez), en la misma collación de S. Bartolomé, por lo que se puede situar hacia estas fechas el comienzo de las obras. El 8 de agosto de 1781, Echamorro prorrogará dicho arrendamiento por tres años más.

31 de enero de 1781: Pedro de San Martín, maestro mayor de obras del Ayuntamiento, cita en un informe municipal a Antonio de Figueroa como maestro responsable de la obra de S. Bartolomé, que en esa fecha se hallaba $\operatorname{parada}^{13}$.

19 de agosto de 1782: El procurador de fábricas, en nombre de la de iglesia parroquial de S. Bartolomé, expone que la nave lateral que se ha de habilitar como iglesia durante la obra está concluida, solicitando la visita del maestro mayor a fin de reconocer si se puede trasladar allí a S.M. Sacramentado.

12 Como se puede comprobar, la iglesia finalmente construida resulta bastante fiel al proyecto de Antonio de Figueroa, tanto en la estructura y organización generales como en la decoración interior con el orden dórico, usando las proporciones dupla (2/1) en los alzados de los arcos torales y sesquiáltera (3/2) en los de los intercolumnios, habituales en sus obras. En cuanto a la nave central, le otorgó más altura y esbeltez de lo normal, utilizando la proporción super quatripartiens quintas (9/5) más media vara, debido muy posiblemente a la existencia de un cuerpo adosado a cada una de las naves laterales, lo cual obligaba a dotar de un mayor desarrollo en longitud al tejado. Y como destacada alteración respecto del proyecto, a la media naranja ciega prevista se le añadió un tambor en el que se abrieron cuatro ventanales, modificación que, por otro lado, se dio en más de una ocasión en las obras de las nuevas iglesias.

13 Es decir, durante esta primera fase de la construcción, Antonio de Figueroa es el maestro mayor del arzobispado encargado de supervisar las obras y el carmonense José Echamorro el maestro ejecutor. 
20 de agosto de 1782: Informe de reconocimiento del maestro mayor del Deán y Cabildo, José Álvarez, quien declara rematada la nave lateral y que la obra está "executada con arreglo, con primor y aseo, y capaz para los oficios Divinos", solicitando que, aunque la obra se vaya a parar "por no haver dinero para seguirla", se construyan los arcos intercolumnios compañeros de los labrados, para que así "los enjugos que deven tener en los arcos sean igualmente"14.

22 de agosto de 1782: Se otorga licencia para que se bendiga la nave y se traslade a S.M.

Las obras permanecen diez años paralizadas.

\section{REANUDACIÓN DE LAS GESTIONES PARA PROSEGUIR LAS OBRAS (1792)}

3 de agosto de 1792: Se nombra por Director de la prosecución de las obras al abad de los beneficiados parroquiales y como maestro albañil a Rafael de Ledesma.

Primeros de septiembre de 1792: Escrito de Rafael de Ledesma, maestro alarife, al Arcediano de Sevilla y a la Diputación de Negocios del Cabildo catedralicio, en el que denuncia que habiendo sido nombrado como maestro para la continuación de las obras, está padeciendo las difamaciones del cura y del abad de los beneficiados parroquiales. Éstos ponen en tela de juicio su reputación, adquirida en obras de iglesias del arzobispado como las de Bormujos, Valencina, El Real de la Jara, Salteras, Cantillana, ElViso, Mairena y Huévar, entre otras, ya que preferían "sea dirixida esta obra por uno de los famosos Maestros del Cavildo de V.S. quales son Alvares, Rosales...".

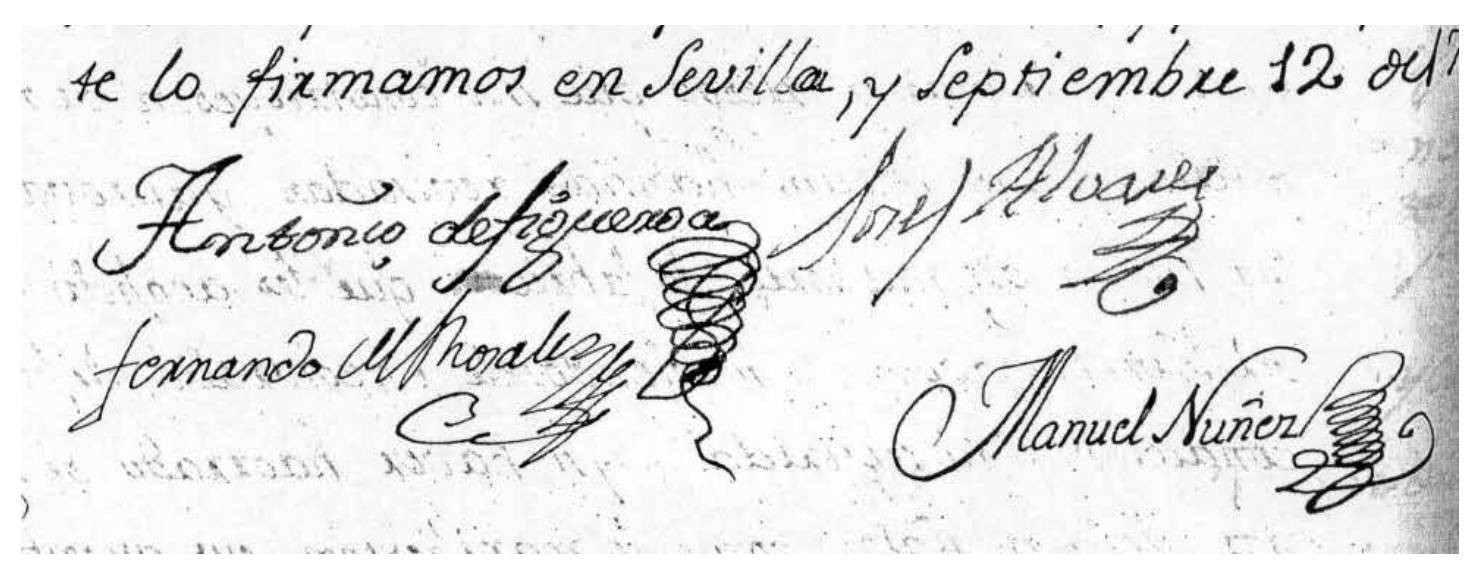

Firmas de los cuatro maestros mayores, en orden de antigüedad en el cargo, al pie del escrito redactado a favor de Rafael de Ledesma de puño y letra de Manuel Núñez. AGAS, Fondo Arzobispal, Sec. III, sign. 11473.

14 El expediente no especifica de cuál de las naves laterales se trata, aunque dado que, como se verá, la primera portada que se remató fue la de la epístola, lo lógico es que fuera ésta. 
12 de septiembre de 1792: Los maestros mayores del arzobispado Antonio de Figueroa, José Álvarez, Fernando Rosales y Manuel Núñez salen en defensa de Rafael de Ledesma, dando testimonio escrito de su buen hacer profesional, conducta y pericia en el oficio, declarando no hallar razones para que éste no pueda concluir la obra de San Bartolomé.

5 de octubre de 1792: El procurador mayor de los Sres. Deán y Cabildo declara que la mayor parte de lo labrado hasta la fecha en San Bartolomé (1780-82) lo había ejecutado José Echamorro, quien fue nombrado por dichos Sres. Siendo sustituido por Juan Romero, tras la ausencia de aquél.

8 de octubre de 1792: El provisor autoriza que la dirección de la obra recaiga en Manuel Núñez, mandando se le entreguen los planos.

7 de diciembre de 1792: El maestro Núñez amenaza con renunciar a la Dirección de las obras, pues el clero de San Bartolomé se entromete tanto en ellas que impide poner en práctica sus órdenes, además de haber conseguido que se suspendiese al maestro ejecutor Rafael de Ledesma y se desistiese de la Administración el licenciado D. Miguel Morán Benavides.

8 de diciembre de 1792: D. Miguel Morán Benavides, ex-Administrador de la obra, denuncia que el clero de San Bartolomé anduvo conspirando desde el momento del nombramiento de Rafael de Ledesma (septiembre 1792), a fin de que fuesen José Echamorro y Pedro de San Martín "el menor" los maestros directores, a lo que se ofrecían desinteresadamente. El procurador de fábricas solicita al provisor que advierta al clero de la parroquia que no se entrometa ni en la obra ni en la selección de albañiles. Se nombra como nuevo Administrador a D. Manuel de Torres, presbítero, y se ratifica a Manuel Núñez en la dirección de las obras ${ }^{15}$.

\section{SEGUNDA FASE DE LAS OBRAS DE LA NUEVA IGLESIA Y FINAL DEL EXPEDIENTE DIOCESANO (1793-1796)}

\section{0 de enero de 1793: Se reanudan las obras de San Bartolomé.}

1 de febrero de 1793: Manuel Núñez pasa a reconocer lo ejecutado siguiendo los planos y condiciones que al principio dio Antonio de Figueroa, solicitando la presencia de éste en las obras para determinar su prosecución y decidir qué hacer con la pared gualdera del evangelio.

15 de febrero de 1793: Informe de reconocimiento de Antonio de Figueroa, a fin de decidir el remedio que se debe dar a la referida gualdera. Le acompañan Núñez y el Administrador. Figueroa justifica los derribos de la gualdera

15 Al igual que queda claro que Manuel Núñez siguió con la dirección de las obras, el expediente precisa que Rafael de Ledesma fue destinado a la obra que se iba a principiar en la iglesia de San Gil.Y por otro lado, lo cierto es que a pesar de los sibilinos intentos de José Echamorro de hacerse con la construcción del templo, no lo conseguiría hasta cuatro años después, una vez finalizada oficialmente la segunda fase de las obras. 
del evangelio y del testero y bóveda del altar mayor, ésta "por lo reducida de su situacion y poca elevacion en que se hallaba dicha Capilla maior, faltando a la uniformidad y buen Arte de la Adquithectura con los Arcos Torales de la Nave del medio y Cruzero...()...no hay que dudar ser indispensable dejar de construir la nueba Capilla maior, dandole la proporcion y azpecto que han de observar dichos Arcos Torales: $Y$ en quanto su Pabimento, se deverá formar el testero a la tirantes del de la Capilla de la Virgen de la Alegria, valiendose del terreno de una casa contigua a la espalda de la misma Yglecia".

Por estas fechas, D. José Teodoro de Urruchi, D. José Suárez y D. Fco. de Paula García Coronado, "vecinos de esta Ciudad y Feligreses de la Collacion de $S^{n}$ Bartolome", denuncian ante la "Diputacion Secreta del Ilustrisimo Cabildo" lo perjudicial que resulta para la perfección de la iglesia, la casa que hace esquina con la callejuela, principalmente "porque es el sitio en donde debia Fabricarse la Torre, segun y como se acostumbra en la mayor parte de las Yglesias, y que ademas el campanario que hoy dia existe, no puede quedar en el sitio en que se halla por la mayor elevacion que ha de tener la media Naranja"16.

8 de mayo de 1793: Informe de reconocimiento de Manuel Núñez, en el que declara que "aviendose de aser torre como me parese indispensable es el sitio que ocupa dicha Casa el mas a el proposito". La casa en cuestión es de capellanía y está ubicada a los pies de la iglesia, al lado del evangelio, formando la esquina entre la plazuela y la calleja. También añade que, como ha dicho Figueroa, hay que tomar parte de la casa contigua al altar mayor, para que no quede dicha capilla "mui estrecha y fuera de arte"17.

8 de julio de 1793: Informe de Antonio de Figueroa de reconocimiento de la citada casa de la capellanía, proyectando lo conveniente para la ampliación de la iglesia. Figueroa es de la opinión de que se agregue dicha casa al recinto del nuevo templo, en cuya situación se deberá formar la nueva torre. El maestro presenta el plano de la obra, trazado por él, "con cuias reglas y dimenciones se dio principio y se va continuando el templo", proyectando la torre a los pies, junto a la nave del evangelio, pero sin llegar a formar la esquina. Antonio de Figueroa explica que "haviendo sido el pensamiento primero del que declara formar la nueba Torre en el propio angulo de la esquina que es lo que a rrigor y vajo del mejor arte se devia observar, a fin de que desde su formacion se señorearan las dos Fachadas de su esquadra, se halló con el escollo de quedar mui a trasmano la entrada para su uso y manejo de las campanas, como por la parte de sitio que se venia a innutilisar perdiendo la comodidad que por la misma escalera de la Torre

16 El interesante escrito de estos implicados feligreses, además de denunciar el estorbo que suponía dicha casa, revela que ya se había decidido dotar a la cúpula de mayor empaque que el inicialmente previsto, lo que comprometería la funcionalidad de la espadaña existente hasta la fecha.

17 Esta declaración de Manuel Núñez recoge, pues, la queja vecinal en relación con la necesidad de que la nueva iglesia dispusiera de torre (en lugar de una simple espadaña) y de su posible ubicación, proceso decisorio en el que se emplearán los próximos meses. 
se trancitara a la Tribuna, motivos para mudar de pareser y demostrarla contigua al Pie de la Nave del Evangelio". Figueroa da las condiciones para ejecutar la cimentación de la torre, cuya caña, atirantada con la calleja, llevará un zócalo de dos varas o poco más con su moldura de media tercia entrante. Este lado de la torre continuará su altura, dejando resaltados los extremos, ubicando en él ventanas o claraboyas "hasta que predominen las otras tres fachadas por sima de los texados que a ella se aproximan, en que se iran repartiendo las Luces por dichas tres fachadas, hasta llegar a sentar la cornisa o imposta para el movimiento del cuerpo de campanas, que teniendo dicha Torre cinco varas y dos tercios por cada una de sus fachadas, se deverá elevar el cuerpo basto o caña de que se va hablando, veinte y dos varas y dos tercias, incluso el peralte de la dicha Ymposta o cornisa, que asi en este adorno como en el que corresponde al referido cuerpo de campanas y su coronacion lo deja el que declara a el arbitrio del Maestro maior que dirije esta obra". La escalera será de idas y ojo abierto, sobre hocinos de tabique doble, finalizándose "con el Arte solides y aceo que corresponde y se deja entender". Valora la construcción de la torre entre sesenta y sesenta y cinco mil reales de vellón.

9 de julio de 1793: Informe de reconocimiento del maestro mayor de carpintería Francisco del Valle.

29 de julio de 1793: Sorpresivamente, recién cumplidos los sesenta años de edad fallece el maestro mayor Antonio de Figueroa.

7 de noviembre de 1793: Informe de reconocimiento de Francisco del Valle, en el que informa que se hallan sin cubrir la nave central, el cabecero, brazos del crucero, capillas colaterales y sacristía.

11 de noviembre de 1793: Informe de reconocimiento del maestro mayor Fernando Rosales, indicando el sitio más apropiado para trasladar la capilla de Ntra. Sra. de los Dolores y dando las instrucciones para su ejecución ${ }^{18}$.

22 de marzo de 1794: Informe de reconocimiento del maestro mayor Fernando Rosales, que realiza "teniendo presente las condiciones y Plano del proyecto de todas sus obras". Rosales da las condiciones para ejecutar la portada del evangelio, "para que uniforme esta con la nueva construida a el lado de la Epistola"19, indicando que "se le devera colocar sus Pilastras y demas adornos que en el dia tiene la compañera construida a la otra parte". En cuanto a los muros exteriores, "deveran guardar sus Paredes los mismos movimientos de Soclo y Pilastras que tienen las que estan construidas a el lado de la Epistola". Finalmente, por lo que respecta a la

18 Fernando Rosales (1754-1830) fue el maestro mayor del arzobispado habitualmente encargado de concluir las obras diocesanas que dejó sin finalizar Antonio de Figueroa a su muerte.

19 La expresión "nueva" de Rosales no aclara si la portada de la epístola fue proyectada por él y ejecutada entre noviembre de 1793 y marzo de 1794, fecha en la que da las condiciones para labrar la portada del evangelio, o había sido proyectada por Antonio de Figueroa para usar provisionalmente dicha nave como iglesia. En cualquier caso, sus características formales apuntan a la autoría de Figueroa. 
torre, Rosales "Dixo ser combeniente se construia la Torre en el mismo angulo que forma la fachada con este costado"20.

19 de mayo de 1794: Informe de reconocimiento de Fernando Rosales, corrigiendo el proyecto de las oficinas parroquiales, cuarto taller y otras dependencias.

6 de septiembre de 1794: Informe de Fernando Rosales reconociendo si las obras ejecutadas en la capilla de Ntra. Sra. de los Dolores van con arreglo a lo proyectado.

1 de mayo de 1795: Informe de reconocimiento del maestro mayor José Álvarez, prescribiendo el sitio y el modo de construir las bóvedas para entierros.

6 de noviembre de 1795: Informe de reconocimiento del maestro mayor de carpintería Francisco del Valle.

Mayo-junio de 1796: el clero de San Bartolomé, representado por D. Roque Sánchez y D. Antonio Granados, beneficiados, y por D. Ramón Márquez Esparragosa, sochantre, comunica al arzobispado que la iglesia se halla concluida pero la torre está sin terminar, "sin poder usarse de ella por la falta de elevacion que se requiere para que puedan oirse las campanas", lo que se conseguirá si se le confiere a uno de ellos la Administración de lo que falta por hacer. Añaden que en ello "puede haver mucho haorro valiendose los suplicantes del Maestro mayor de la Ciudad $D^{n}$ José Echamoros, que por afecto a dicha Yga $g^{a}$ hará graciosamente las visitas que sean necesarias", evitándose la fábrica parroquial el jornal del maestro y de un oficial. Por todo lo cual solicitan que aquél sea nombrado a tal fin ${ }^{21}$.

20 Es decir, es a Fernando Rosales a quien se debe la ubicación definitiva de la torre en la esquina del edificio, separada del cuerpo de iglesia, pues Antonio de Figueroa prefería adosarla a la nave colateral del evangelio, como ya se vio. Por tanto, bajo sus prescripciones (aunque basadas en las condiciones generales de Figueroa de julio de 1793), y la asistencia de Manuel Núñez, se ejecutaría el fuste de la torre entre 1794 y 1796, justo hasta donde comienza el entablamento que lo corona.

21 José Echamorro (1751-1825), quien desde 1786 ostentaba el cargo de maestro mayor de la Ciudad, había adquirido cierto prestigio como perito tercero del arzobispado en las discrepancias y deficiencias acaecidas en varias obras dirigidas por los maestros mayores diocesanos. Así por ejemplo, en octubre de 1790 informaba sobre el modo de reparar las ruinas que presentaba la torre de la recientemente labrada iglesia de Algodonales. En julio de 1794 daba su dictamen relativo a los importantes daños aparecidos en el templo parroquial de Peñaflor, aún en ejecución, salvándolo del derribo al que lo había condenado el maestro mayor Fernando Rosales. Y en octubre del mismo año fue nombrado para dictaminar sobre la conveniencia de las obras prescritas para las portadas de la utrerana iglesia de Santa María por dicho maestro, con el que había quedado enemistado desde su intervención en Peñaflor. Hombre "de buen cuerpo Reecho color trigueño claro pelo castaño ojos Pardos cerrado de barba", polémico y de vehemente carácter, legó diversas notables obras, las más representativas de las cuales son la portada sur de Santa María, la Cilla del Cabildo y las reformas de las antiguas Casas Capitulares y de la Puerta de Córdoba, todas ellas en Carmona, las portadas de las utreranas iglesias de Santa María de la Mesa y Santiago, los campanarios de la parroquial de Peñaflor y de San Bartolomé de Sevilla, y también en esta última ciudad, la iglesia y torres de San Ildefonso. 


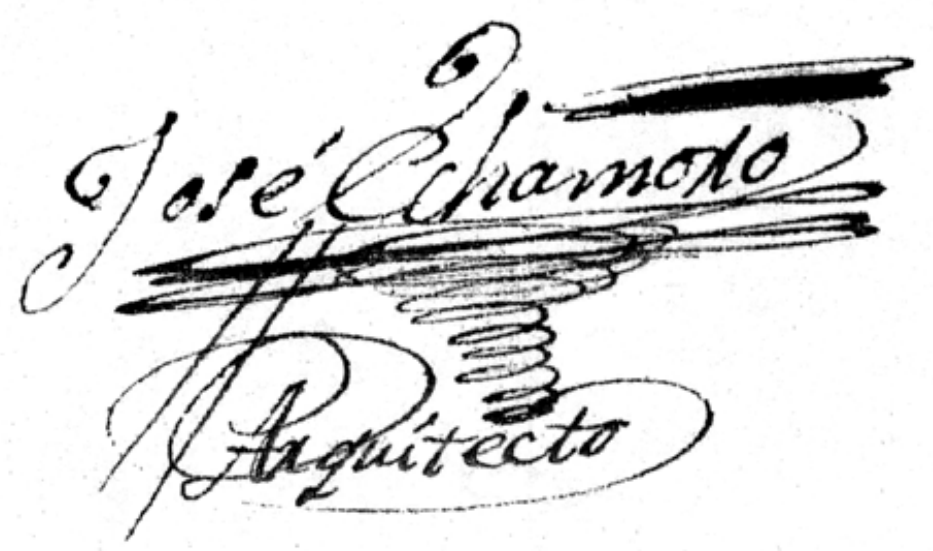

Firma de José Echamorro en 1796, cuya rúbrica reivindica un título que el maestro carmonense nunca obtuvo y cuya atribución originó, además de continuados pleitos durante su vida profesional, el rechazo de los arquitectos titulados, que no veían en el más que un maestro albañil. AGAS, Fondo Arzobispal, Sec. III, sign. 10350.

10 de junio de 1796: El procurador del Deán y Cabildo declara que la obra está oficialmente terminada "y gastado todo lo que los diezmos podrán producir", solicitando pase a reconocerla y a dar su cumplido el maestro mayor que esté en turno.

15 de junio de 1796: D. Ramón Márquez Esparragosa, sochantre parroquial, otorga escritura como Administrador de la obra de San Bartolomé22.

11 de julio de 1796: Informe de reconocimiento de Fernando Rosales de la obra ejecutada. El maestro la halla finalizada en todas sus partes, "a ecepcion de la Torre, Patinillo o campo santo y remate de lo interior del quarto taller o trancito a dicha Torre". Por lo cual indica que, una vez colocados los retablos, se puede usar la iglesia sin reparo alguno, pues no encuentra en ella "cosa alguna en contra a lo principal de sus proyectos", dando por cumplidas las obras, a excepción de la torre y piezas contiguas referidas. Rosales valora en 45.000 reales lo que se necesita invertir para concluirlas.

12 de julio de 1796: Informe de reconocimiento de Francisco del Valle, quien también da su cumplido a las obras.

El expediente finaliza con la Cuenta General de las obras presentadas por el Administrador D. Manuel de Torres, quien estuvo a cargo de las mismas algo más de tres años, concretamente entre el 20 de enero de 1793 y el 31 de mayo de 1796.

Durante todo este período, Manuel Núñez firma las liquidaciones y certificaciones, como maestro director de las obras.

22 Sería a partir de este momento cuando volvería a retomar las obras de San Bartolomé José Echamorro, que finalizaría las dependencias interiores, aunque dejó inconclusa la torre. 


\section{HIPÓTESIS SOBRE LA CONTINUACIÓN DE LAS OBRAS DE LA NUEVA IGLESIA 1796 - ¿1800?}

Aunque el expediente diocesano finaliza aquí, resulta lógico pensar que, una vez concluida esta segunda fase de las obras, y habiendo sido nombrado nuevo administrador para su prosecución y remate D. Ramón Márquez Esparragosa, favorable a la designación de José Echamorro como "arquitecto" director, el maestro carmonense vería finalmente correspondidos sus deseos de concluir el templo que él mismo había comenzado a levantar dieciséis años atrás, pues el administrador tenía la facultad de elegir al maestro de la obra. Conjetura que por otra parte queda refrendada por el remate que presenta en la actualidad la torre parroquial, indubitablemente debido a Echamorro. Así, sobre la caña construida bajo la supervisión de Fernando Rosales, un potente entablamento dórico bajo volada cornisa sirve de transición entre aquélla y el cuerpo de campanas, haciendo las veces de imposta. Dicha solución compositiva está tomada de la torre parroquial de Peñaflor, cuyo fuste había rematado de forma similar el maestro ecijano Antonio Caballero en 1786, siendo designado Echamorro por la diócesis para la finalización de dicha torre desde el cuerpo de campanas a partir de octubre de 1794. De hecho, por estas fechas de mediados de 1796, aún se estaba ejecutando el segundo de los tres cuerpos que componen el campanario de Peñaflor.

Es más, a partir de junio de 1797, justamente un año después de retomar las obras de San Bartolomé, Echamorro utilizaría la misma solución en el remate de los fustes de las sevillanas torres de San Ildefonso.

Junto con la caña de Caballero para Peñaflor, otra torre serviría de fuente de inspiración para las torres labradas o finalizadas por Echamorro. En septiembre de 1777 el maestro Antonio de Figueroa dio las condiciones para rematar la de la iglesia parroquial de San Pedro, de Carmona, inspirándose miméticamente en los cuerpos renacentistas de la Giralda, aunque barroquizando el sobrio modelo de Hernán Ruiz. En agosto de 1785 ya estaban concluidas las obras, que otorgaron al maestro un más que merecido reconocimiento. Es obvio que esta bella y equilibrada intervención en su ciudad natal causaría la admiración de Echamorro, pues la reprodujo en Peñaflor años más tarde en clave clasicista sobre la preexistente caña, constituyéndose en modelo para las torres que proyectó posteriormente. De esta manera, el cuerpo de campanas de San Bartolomé es una copia fidedigna del "original" peñaflorense, del que sólo se distingue en el cambio de materiales de algún elemento y en el revestimiento que recubre las columnas de esquina, que había rematado en ladrillo visto en Peñaflor.

Evolucionados estéticamente se muestran los campanarios de San Ildefonso, en Sevilla, cuyas torres son más fieles en conjunto a las de Peñaflor, al haberlas labrado Echamorro desde cimientos, si bien no muestran, ni mucho menos, la gracia y armonía de proporciones del modelo peñaflorense. 


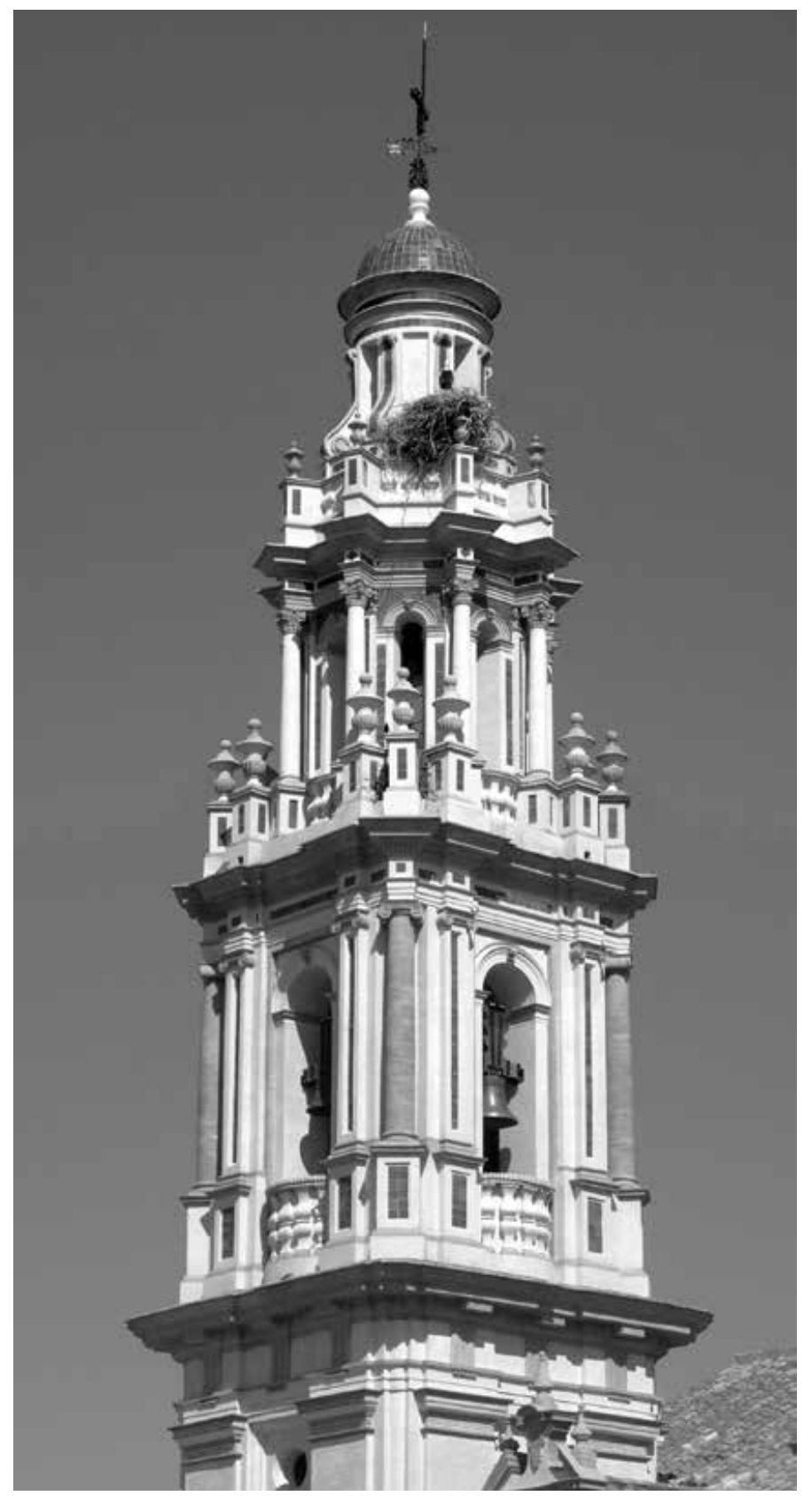

Remate de la caña y cuerpos superiores de la torre de San Pedro, de Peñaflor (Sevilla), finalizada en 1798. La perfecta conjunción de ambos elementos, fuste y campanario, a pesar de que sus autorías son debidas a Antonio Caballero y José Echamorro, respectivamente, confiere a esta pieza una apariencia unitaria de una esbeltez y belleza incuestionables. Fotografia del autor.

Sin embargo, la torre de San Bartolomé quedaría inconclusa, muy posiblemente por la falta de caudales, circunstancia esta de los recursos que también se producía en la de Peñaflor, aunque en otro sentido. Habiendo sido nombrado Echamorro para finalizarla, el 10 de febrero de 1797 informaba Fernando Rosales de las libertades que se estaba tomando aquél en su remate, cuyo gasto había sobrepasado ya en 40.000 reales el presupuesto previsto, faltando aún por invertir otros 15.000 reales al menos, lo cual provocó, en un episodio más de la rivalidad existente entre ambos maestros, la destitución de Echamorro de la obra de Peñaflor. No obstante, habiendo ofrecido sus servicios graciosamente a la fábrica parroquial (al igual que hizo en San Bartolomé), la siguió supervisando extraoficialmente hasta su total conclusión. 

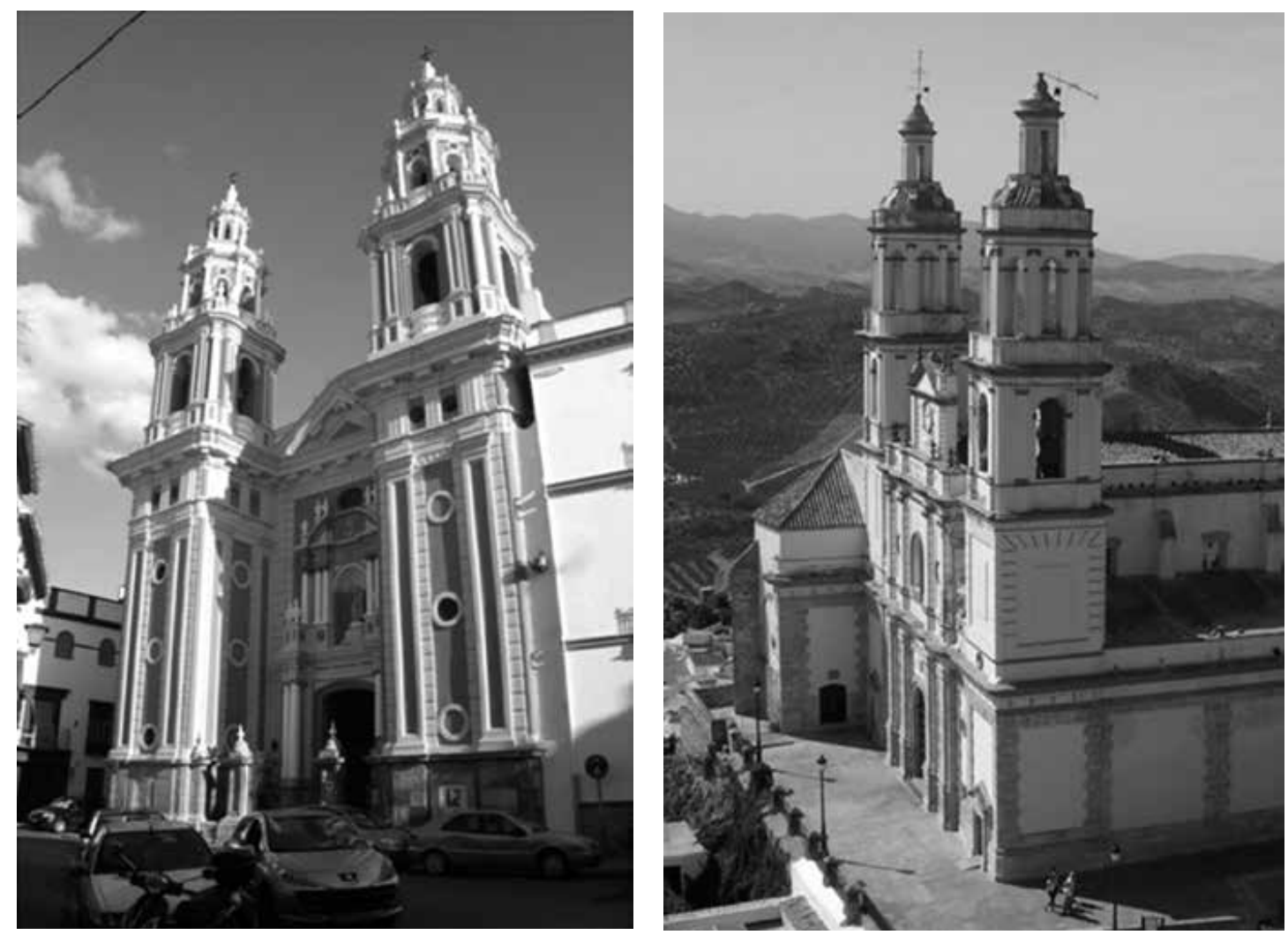

Torres de San Ildefonso, de Sevilla (izqda.), proyectadas por José Echamorro, y de Ntra. Sra. de la Encarnación, de Olvera (Cádiz), atribuidas al mismo maestro. Fotografias del autor.

Debido a la escasez de recursos para la obra de San Bartolomé, Echamorro podría haber llevado a cabo un cambio de planes para conseguir rematar dicha torre, como parece apuntar el banco construido sobre el cuerpo de campanas siguiendo los planos verticales de éste, de lineas estrictamente rectas y más esquemático que el precedente de Peñaflor y el posterior de San Ildefonso, y muy parecido al ejecutado en la iglesia de Olvera, atribuida al maestro carmonense. La existencia de dicho banco induce a pensar que Echamorro iba a optar por una solución mucho más económica y simplificada del modelo (como haría Santiago de la Llosa en la torre de San Miguel de Marchena), o bien por rematarla con el tradicional chapitel piramidal ochavado sobre rebanco de igual planta, pero nunca con el remate que se pretende reponer ahora, posible obra del arquitecto diocesano Manuel Portillo y Navarrete, fechable en la década de 1860-7023. Dos

23 Discípulo de Juan Miguel Inclán Valdés, Manuel Portillo y Navarrete (1796-1871) obtuvo el título de arquitecto en la Real Academia de San Fernando el 24 de abril de 1831 y coincidió en Sevilla en sus inicios profesionales con Melchor Cano, Mariano del Río y Salustiano Ardanaz. En 1854 fue nombrado arquitecto del arzobispado, realizando numerosas intervenciones en los templos de la archidiócesis, y entre 1859 y 1863 ocupó el cargo de Arquitecto Provincial. Dirigió, entre otras, las obras del desaparecido Teatro de San Fernando, que estuvo ubicado en la calle Tetuán, y las de la Pirotecnia Militar, ambas iniciadas en 1847. Véase SUÁREZ GARMENDIA, José Manuel: "Arquitectura y urbanismo en la Sevilla del siglo XIX", Diputación de Sevilla, 1987, p. 109-110 y ss. y LINARES GÓMEZ DEL PULGAR, Mercedes: "Balbino Marrón y Ranero, arquitecto municipal y provincial de Sevilla (1845-1867)", Diputación de Sevilla, 2016, p. 88-89 y ss. 


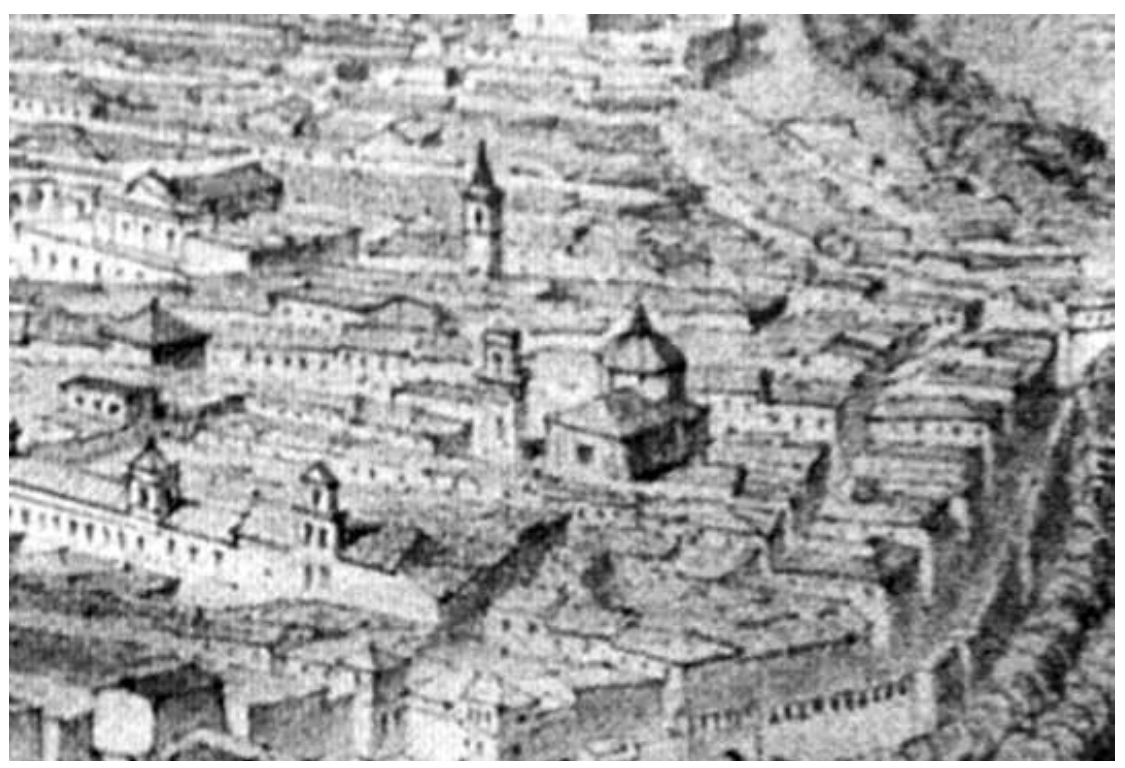

Pormenor de la vista de Sevilla desde el sur, de la serie "L'Espagne a vol d'oiseau" de A. Guesdon, en la que se aprecia la ausencia de remate en la torre de San Bartolomé, lo cual confirma la más que tardía adscripción ochocentista del cupulín desaparecido. Colección particular.

circunstancias permiten atribuir la autoría y la datación de la coronación de la torre. En primer lugar, documentalmente consta que Portillo estaba proyectando por esos años obras en San Bartolomé24. Y por otro lado, la iconografía contemporánea no deja lugar a dudas. En efecto, en una de las dos láminas dedicadas a Sevilla en "ĹEspagne a vol d'oiseau", del dibujante francés Alfred Guesdon, fechables hacia $1853^{25}$, se muestra la torre huérfana aún del cupulado remate. Sea como fuere, Echamorro falleció en 1825 sin verla finalizada.

En resumidas cuentas, la actual iglesia de San Bartolomé responde en su disposición general y aspecto interior al proyecto presentado por Antonio de Figueroa el 10 de enero de 1780, cuya primera fase de las obras sería ejecutada sucesivamente por los alarifes José Echamorro y Juan Romero entre mayo de ese año y agosto de 1782, siendo el propio Figueroa el maestro mayor encargado de supervisarlas.

Tras permanecer diez años paralizadas, durante los cuales se había usado como iglesia una de las naves laterales habilitada para ello, el 20 de enero de 1793 se reanudan las obras del templo, siendo dirigidas por Manuel Núñez, que sustituyó a Rafael de Ledesma, y supervisadas correlativamente por los maestros diocesanos Antonio de Figueroa y Fernando Rosales, al que se deberán las modificaciones introducidas sobre el proyecto y la idea inicial de Figueroa, entre

24 AGAS, Fondo Arzobispal, Sec. III, sign. 11330: "Albañileria: En el reparo hecho y blanqueo en el año de $1860 \ldots . . .50$ rs... Al arquitecto Señor Portillo por el reconocimiento y presupuesto de la Obra de la $Y g l^{a} \ldots 120 r^{\prime \prime}$.

25 Véase al respecto GÁMIZ GORDO, Antonio/GARCÍA ORTEGA, Antonio Jesús (2018):“La vista aérea de Córdoba dibujada por Alfred Guesdon en 1853", Archivo Español de Arte, vol. 91, n 361, Madrid, pp. 29-45. 


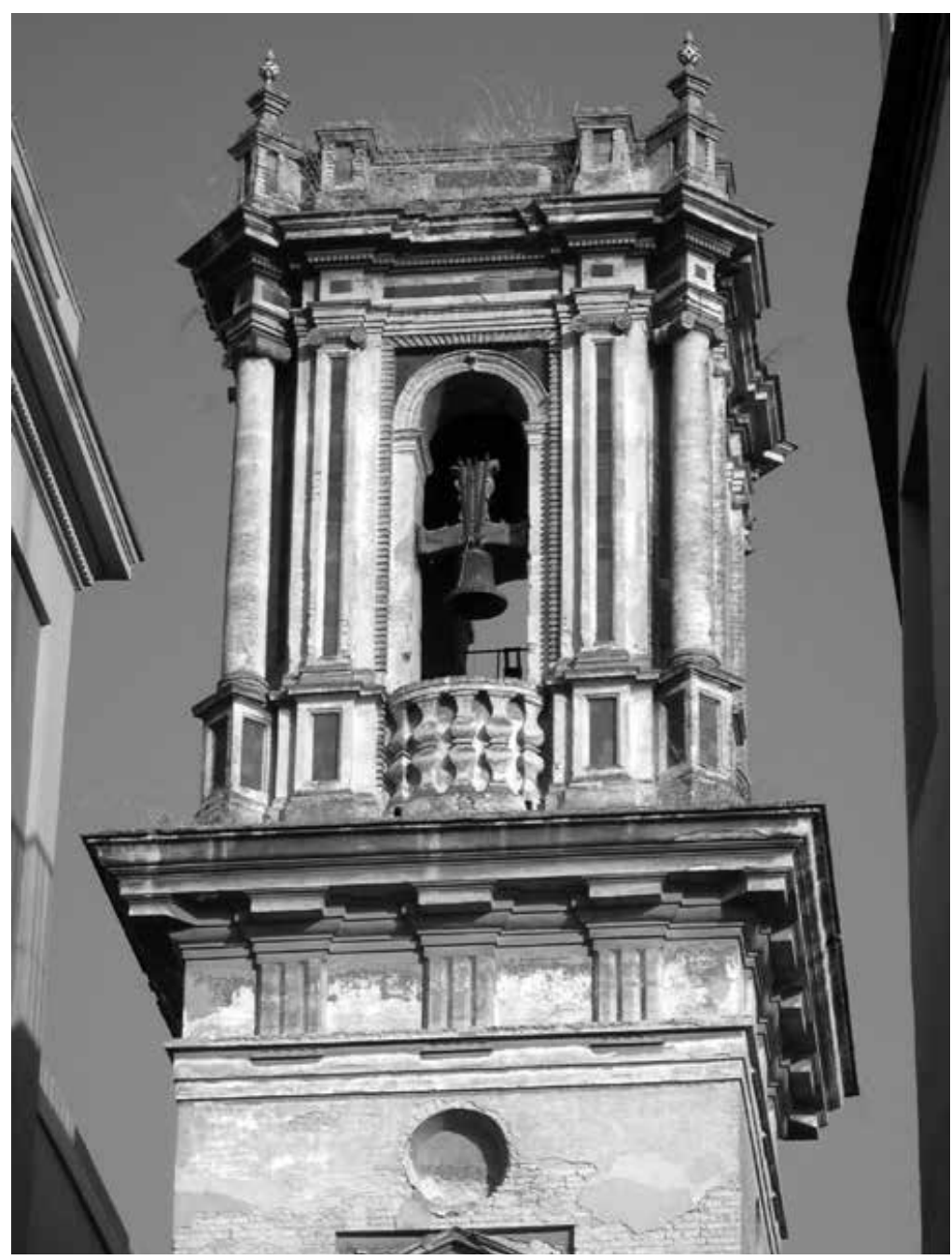

En el campanario de San Bartolomé son evidentes las similitudes con la torre de Peñaflor, tanto en la coronación del fuste como en el cuerpo de campanas, gemelo del de aquélla. Problemas económicos impedirían a Echamorro rematarlo siguiendo el modelo original. Fotografía del autor.

ellas la ejecución del tambor con ventanales en el cuerpo de luces y la definitiva ubicación de la torre en la esquina suroeste del templo. Rosales daría también las condiciones para labrar la portada principal, las fachadas y revestir el edificio con esgrafiados de cantería fingida similares a los que muestra la Escuela de Cristo, que proyectó en 1796. El 31 de mayo de ese año se dio por finalizada la segunda fase de las obras de San Bartolomé, quedando por rematar el cuarto taller, patinillo o camposanto, la torre y el tránsito a ésta desde la iglesia.

Se puede concluir, por tanto, que el actual aspecto de San Bartolomé responde en su interior al proyecto de Antonio de Figueroa, mientras que exteriormente (salvo posiblemente la portada de la epístola) refleja todo la intervención de Fernando Rosales.

En cuanto a la torre, el 8 de julio de 1793 Figueroa dio las condiciones para ejecutar el fuste, dejando al albedrío del maestro director (Manuel Núñez) el diseño del cuerpo de campanas y su remate. Sin embargo, Rosales desplazó posteriormente su ubicación al ángulo, supervisando la ejecución del fuste, 
finalizando su intervención con su informe de 11 de julio de 1796. A partir de esta fecha tomaría la dirección de las obras José Echamorro, que coronó la caña con un entablamento dórico y labró el cuerpo de campanas a imagen del que había construido recientemente en Peñaflor.

\section{CONCLUSIONES}

La restauración de la torre de San Bartolomé invita a reflexionar sobre cómo intervenir hoy en día en arquitecturas de épocas pasadas. En relación con la propuesta aprobada para reponer el remate conocido a través de la documentación fotográfica, y admitiendo el resultado de la presente investigación, que lo data más de medio siglo después de ser proyectada la torre y sin relación estilística, formal ni conceptual con su arquitectura, cabría hacer algunas consideraciones. Por ejemplo, parece lícito replantearse la conveniencia de "rescatar" un anacrónico diseño ochocentista que con el tiempo terminó cayendo, como si la propia torre se lo hubiese sacudido de encima por inadecuado. Y con el conocimiento de la arquitectura del momento y por ende del edificio, pero desde postulados teóricos y patrimoniales contemporáneos y con la arquitectura de nuestra época, formular propuestas alternativas susceptibles, claro está, de recibir el visto bueno de la Comisión Provincial de Patrimonio.

No obstante, habiendo precisado que la honestidad que supone un"modus operandi" basado en la comprensión de la arquitectura del pasado y en la confianza en la del presente, es un concepto clave para dialogar con arquitecturas pretéritas e intervenir sobre ellas (como ya en el siglo XVI tenía muy claro el maestro Hernán Ruiz), en el caso concreto de la historia constructiva de la inconclusa torre de San Bartolomé se dan dos circunstancias que no pueden ser soslayadas, y que constituyen una aportación del presente artículo: en primer lugar, como ya ha quedado dicho, el remate autorizado por la Comisión Provincial de Patrimonio respondería claramente a una intervención ochocentista que no presenta relación de ningún tipo con el preexistente soporte. Pero resulta que, además, se conoce tanto al autor del campanario -José Echamorro- como el modelo de torre que éste venía ejecutando coetáneamente, antes y después, a la de San Bartolomé. Reflexionando, pues, sobre todo lo anteriormente expuesto, y teniendo en cuenta el largo período temporal que lleva sin disponer de él, ¿tiene sentido "rescatar" del limbo, reconstruyéndolo, un anacrónico remate proyectado décadas después que la torre, sólo por haberla coronado durante cierto tiempo, conformando además un conjunto de discutible estética? ¿Sería ésta la única propuesta a la que la Comisión Provincial de Patrimonio daría el visto bueno? Una vez decididos a re-instaurar, es decir, a reconstruir, ¿no resultaría igual de lícito y honesto concluir la torre en base al modelo, perfectamente conocido, del arquitecto que la proyectó al tiempo de su construcción? Ejemplos similares no faltan al respecto en la actualidad. Al fin y al cabo, puestos a retroceder en el 
tiempo para rehacer un elemento de mediados del XIX, ¿por qué no desandar algunos años más, hasta 1796, recuperando el diseño original? Y si ello no fuera posible por suponer un coste excesivo ${ }^{26}$, y puesto que se está pretendiendo reinstaurar como original un remate que no lo era, ¿no sería admisible, en aras de favorecer la uniformidad estilística, rematar la torre de San Bartolomé con el tradicional chapitel de base octogonal, característico de la segunda mitad del

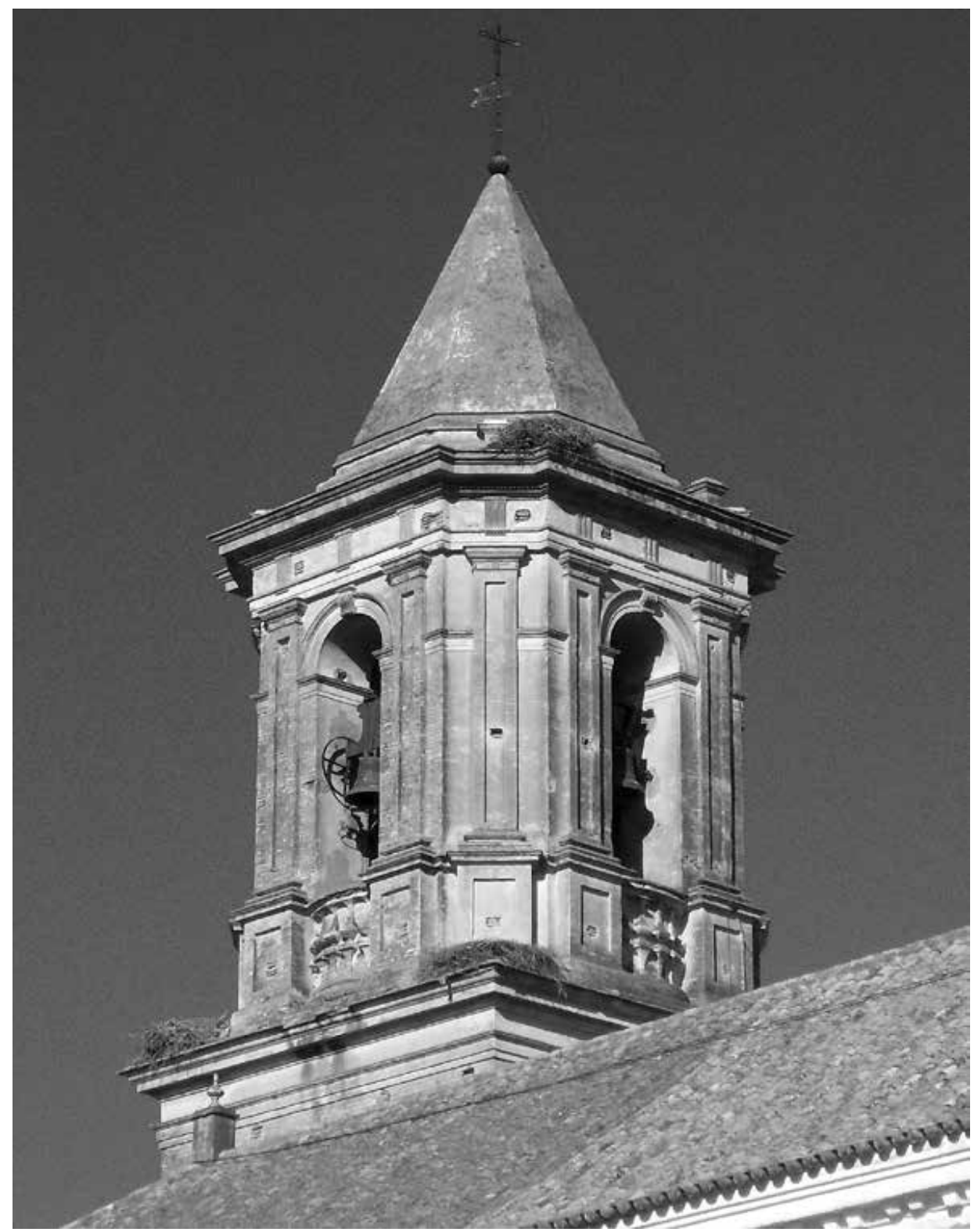

Campanario de la iglesia de la Asunción, de Cantillana (Sevilla), proyectado y construido en las primeras décadas del XIX. La llegada del nuevo siglo no significó un radical abandono de los modelos arquitectónicos dieciochescos, aunque sí una mayor contención ornamental. Fotografía del autor

${ }_{26}$ Como se ha visto, el modelo de torre al que responde la de San Bartolomé está compuesto de fuste más tres cuerpos bastante ornamentados y cupulín de remate, de cuyos elementos sólo se construyeron en aquélla el fuste y el cuerpo de campanas. De hecho, en las torres de la parroquial de Olvera (Cádiz), atribuida al mismo arquitecto, se optaría por ejecutar una versión simplificada del modelo. 
setecientos en la archidiócesis, dejando, por supuesto, nítidamente reconocible el carácter"ex novo" de la intervención? ${ }^{27}$

Para justificar, en contra de estos planteamientos, la reposición del remate ochocentista, podría alegarse que un edificio, y más uno monumental y longevo como el que nos ocupa, constituye algo vivo y en permanente evolución, siendo en cada momento el resultado de todas las intervenciones arquitectónicas a las que ha sido sometido, hasta esa fecha, a lo largo de su historia. Por lo que tal reposición redundaría en recuperar parte del edificio y de su memoria. Sin embargo, la que se pretende reponer en este caso es una pieza que no sólo no se presupone fruto de una intervención posterior, sino que la propuesta de recuperación considera proyectada originalmente para el templo, cuando la documentación histórica demuestra que no lo fue. Es decir, en San Bartolomé se plantea y autoriza reinstaurar el remate sólo por creerlo, erróneamente, parte del proyecto original del templo. Sin embargo, ¿cómo se produciría la reconstrucción del elemento, cuando no existen planos del mismo? ¿Con qué materiales estaba construido? ¿Son suficientes y fiables las fotografías existentes? ¿Por qué se cayó? ¿Acaso se trataba de un diseño inadecuado estructural o constructivamente?Y si es entonces debida a una intervención del XIX, ¿no actuó honestamente aquel arquitecto al rematar la torre con la arquitectura de su contemporaneidad? Entiendo que sí, aunque a mi juicio parece que por su parte faltó conocimiento y comprensión de la precedente, quién sabe si por una posible falta de "empatía artística", quizá por lo que la arquitectura de la diócesis sevillana del siglo XVIII, incluso la del final de la centuria, significaba para los ochocentistas ${ }^{28}$.

Es obvio que las anteriores observaciones deben entenderse como reflexiones personales sobre la delicada y poliédrica tarea de dialogar con una construcción de otra época para intervenir en ella, aplicada al caso concreto de dotar de remate a la torre de San Bartolomé, labor todavía más ardua y compleja al tratarse de un bien patrimonial. Pero al fín y al cabo, la formulación de propuestas distintas a la prevista en esta intervención no es sino la consecuencia lógica de la adquisición de un mayor conocimiento del edificio y de su historia constructiva, incluso de la finalmente no materializada, que es el objetivo del presente trabajo.

27 La realización del chapitel dieciochesco en las torres de la diócesis hispalense persistía aún entrado el siglo XIX, como lo demuestra el campanario y su remate de la iglesia parroquial de Cantillana, proyectados por el maestro Julián de la Vega en 1802 y ejecutados años más tarde bajo la dirección de Fernando Rosales.

28 Siguiendo la línea de los titulados setecentistas, los arquitectos del XIX, incluidos los que trabajaban para la diócesis hispalense, demostraban no tener muy buen concepto de los maestros mayores dieciochescos, ni de sus obras. Valga como ejemplo el radical comentario del arquitecto académico Eduardo García Pérez, a quien encargó el arzobispado en 1867 la reparación del templo de Alosno (Huelva), construido entre 1784 y 1793 con la intervención de José Álvarez, Antonio de Figueroa y Fernando Rosales, tres de los afamados maestros mayores diocesanos del tardobarroco sevillano. En su informe descriptivo, García Pérez afirmó “...que el templo parroquial de dicha villa carece absolutamente de mérito artístico..." (AGAS, Fondo Arzobispal, Sec. III, sign. 12208). 


\title{
APÉNDICE DOCUMENTAL
}

\section{JOSÉ ÁLVAREZ EXAMINA Y APRUEBA LOS PLANOS Y CONDICIONES REALIZADOS (SEGÚN SANCHO CORBACHO, POR JOSÉ ECHAMORRO), PARA LA NUEVA IGLESIA DE SAN BARTOLOMÉ. SEVILLA, 19.OCT.1779}

\begin{abstract}
ACS, FC, Contaduría, 11667, Exp. 4
Digo yo Joseph Alvarez, que en Cumplimiento de lo mandado por S.Sas. los Ses. de la Diputacion de Negocios del Yllmo. Sr. Dean y Cavildo de esta Sta. Patriarcal Yga . é visto mui por menudo el Plano y Arzado y Condiciones para la Costrucion de la nueva Yga . lo mas de ella, de la Parroquial del Sr. Sn. Bartholomé de esta Ciudad, y por lo que respecta al Orizontal demuestra el citio que oy ocupa $\mathrm{laYg}^{\mathrm{a}}$. y ademas se yncluie en la nueva $\mathrm{Yg}^{\mathrm{a}}$. una Casita que segun pareze se yntenta tomar a tributo, y el Plan está con arreglo y muy vien demostrado y assi mismo los Arzados con el arte y cimetria que corresponde, como tambien las Condiciones para su execucion, Y por lo que respectta a su costo Con arreglo a las Condiziones, Plano y Arzado, le é regulado assiendo todo el Costo a quatro cientos Mill rrs. de von. y nada menos, por que mas vien ha de subir que ha de vaxar de dicha cantidad, y esto es no resultando novedad en los muros que se dizen pueden sucistir en alguna parte de ellos por ser antiguos, y en haviendoles de tocar para Cargarlos pues son quatro o Cinco varas de lavores las que se han de Crecer sobre de dichos muros, puede haver novedad Como va dicho, y assimismo la habrá en su costo, Es quanto se me ofrece declarar sobre el referido particular y segun mi ynteligencia y para que Conste lo firmo en Sevilla en Dies y nueve dias del mes de Octtubre de Mil Setecientos setenta y nueve;
\end{abstract}

Joseph Alvarez 


\title{
ANTONIO DE FIGUEROA, JOSÉ ÁLVAREZ, FERNANDO ROSALES Y MANUEL NÚÑEZ OTORGAN SU RESPALDO A RAFAEL DE LEDESMA, NOMBRADO PARA CONCLUIR LA IGLESIA DE SAN BARTOLOMÉ. SEVILLA, 12.SEP.1792
}

\author{
AGAS, Fondo Arzobispal, Sec. III, sign. 11473, Fol. 146 r-v \\ Yllmo Señor,
}

En cumplimiento del decreto de V.S. que antesede: Desimos los maestros mayores que ael pie de este firmamos que conosemos a Rafael de Ledesma por Maestro aprovado de Alvañileria, y Examinador y Alcalde de Alarifes que asido dos vezes en dicho Arte, y que como tal facultativo aecho varias obras en esta Ciudad y en algunas Yglesias de el Arzobispado, sacando a unas de simientos hasta su conclusion; y a otras conponiendolas con reparos, de mayor riesgo que si se construyesen de nuevo, las quales unas y otras han sido revisadas y aprovadas por los Maestros mayores de fabricas que les a cojido en turno del Arzobispado, no haviendosele encontrado defecto contra condiciones ni seguridad, y si haver haorrado de sus apresios algunos reales, como lo manifiestan sus quentas y declara el Maestro Figueroa quien le a visitado algunas de las dichas.

Mediante lo qual no encontramos los dichos maestros motivo mi reparo para que el sitado maestro Ledesma no pueda seguir la conclusion del Templo de Sn. Bartolome de esta Ciudad, tanto por su Conducta como por la pericia. Y aun quando fuese dicho Artifice de menos merito que lo que es De continuar dicha obra baxo las tres condisiones siguiente nunca podria resultar detrimento a ella, ni a los intereses, pues consisten la primera en que dicha Yglesia se halla con planos y alzados aprovados, y aun echo parte de la obra por lo que no tiene libertad para nuevos proyectos. La segunda porque guardando dicha obra el mismo orden que otra de quarta partes devera ser visitada y dirixida por uno de los maestros mayores del Arzobispado que este en turno; y el tersero porque como dise el dicho maestro Ledesma en su memorial, dexa a los Sres. Benefisiado y Cura el manejo de los intereses de dicha obra; con cuyos tres particulares no puede nunca padeser detrimento la obra ni intereses por su culpa.

Todo lo qual es lo que podemos informar a V.S. sobre el particular que nos manda, y para que conste lo firmamos en Sevilla, y septiembre 12 de 1792

Antonio de Figueroa

Fernando de Rosales
Josef Alvares

Manuel Nuñez 